\title{
Tingkat Kesukaan terhadap Minuman Cocktail Harvey Wallbanger Berbahan Dasar Jus Jeruk Siam Kintamani Segar dan Jus Jeruk Dalam Kemasan
}

\author{
Ni Kadek Eni Juniari \\ Program Studi Manajemen Tata Hidangan, Politeknik Pariwisata Bali \\ Jl. Dharmawangsa, Kmapial, Nusa Dua, Telp.(0361) 773537-38 \\ enijuniari@gmail.com
}

Received: Mei, 2020

Accepted: Mei, 2020

Published: June, 2020

\begin{abstract}
Abstrak
Tujuan dari penelitian ini adalah untuk mengetahui perbandingan tingkat kesukaan minuman cocktail Harvey Wallbanger berbahan dasar jus jeruk siam Kintamani segar dengan jus jeruk dalam kemasan. Teknik analisis data yang dipergunakan adalah deskriptif kualitatif melalui uji organoleptik berupa uji hedonik terhadap indikator yaitu Acidity, Sweetness, Aroma, Colour, Balance, Presentation. Sedangkan panelis pada penelitian ini berjumlah 20 orang yang terdiri dari bartender, akademisi dan panelis agak terlatih yang menyukai minuman cocktail. Hasilnya menunjukkan bahwa minuman cocktail Harvey Wallbanger dengan menggunakan jus jeruk siam Kintamani segar mendapat nilai sebesar 3,30 dengan nilai interpretasinya sangat suka sedangkan minuman cocktail Harvey Wallbanger yang menggunakan jus jeruk dalam kemasan mendapatkan nilai sebesar 2,49 dengan nilai interpretasinya biasa. Dengan demikian minuman cocktail Harvey Wallbanger berbahan dasar jus jeruk siam Kintamani segar lebih disukai dibandingan minuman cocktail Harvey Wallbanger yang menggunakan jus jeruk dalam kemasan.
\end{abstract}

Kata Kunci : harvey wallbanger, jus jeruk, uji organoleptik

\begin{abstract}
The purpose of this study was to compare the level of preference for a Harvey Wallbanger cocktail made from fresh Kintamani Siamese orange juice with packaged orange juice. A descriptive qualitative data analysis through organoleptic tests in the form of hedonic tests on the indicators of Acidity, Sweetness, Aroma, Color, Balance, Presentation was applied. While the panelists in this study were 20 people consisting of bartenders, academics and moderately trained panelists who like cocktails. The results showed that the Harvey Wallbanger cocktail using fresh Kintamani Siamese orange juice got a value of 3.30 with the interpretation value being very favorable, while the Harvey Wallbanger cocktail using packaged orange juice got a value of 2.49 with the interpretation value. normal. This shows that the Harvey Wallbanger cocktail made from fresh Kintamani Siamese orange juice is preferred over the Harvey Wallbanger cocktail which uses packaged orange juice.
\end{abstract}

Keywords: harvey wallbanger, orange juice, organoleptic test 


\section{PENDAHULUAN}

Minuman campuran merupakan salah satu minuman yang cukup diketahui oleh masyarakat baik dari kalangan remaja sampai orang tua, terutama di dunia hospitality industry. Minuman campuran memiliki nilai sejarah, dan perkembangan yang popular, serta minuman ini umumnya dijual di hotel, restoran, maupun bar. Minuman campuran dapat dibedakan menjadi 2 yaitu mocktail dan cocktail. Cocktail adalah minuman yang mengandung bahan berupa alcohlolic drink yang umumnya berupa spirit, salah satu minuman cocktail yaitu Harvey Wallbanger. Harvey Wallbanger merupakan salah satu minuman campuran (cocktail) yang mudah dibuat dengan vodka, galliano dan jus jeruk. Dimana minuman ini pertama kali dibuat di bar-bar yang ada di Amerika pada tahun 1950-an dan sejak itu Harvey Wallbanger menjadi salah satu cocktail klasik.

Menurut Wiantara (2016:190) vodka merupakan jenis minuman beralkohol berkadar tinggi, bening, dan tidak berwarna. Vodka biasanya memiliki kandungan alkohol sebesar 35\% sampai $60 \%$ dari isinya. Pada awalnya vodka dibuat di Rusia dengan cara mendestilasi hasil fermentasi umbi kentang. Namun dewasa ini, vodka telah dapat dibuat dari padi-padian dan dapat diproduksi hampir diseluruh dunia. Menurut Sihite (2006:133) galliano merupakan minuman keras dari Italia dengan flavour herb, vanilla, roots, dan flowers, yang berwarna kuning terang. Nama Galliano tersebut diambil dari nama seorang pahlawan Italia. Galliano memiliki kandungan alkohol sebesar 30\% sampai 42,3\%. Sedangkan menurut Nuraini (2017:193) jus adalah sari buah tanpa ampas yang berasal dari pemrosesan menggunakan juice extractor atau blander. Umumnya bahan yang digunakan untuk jus adalah buah dan sayuran. Menurut Muzaki (2016:53) jus jeruk mengandung antioksidan, jeruk juga padat vitamin C. Nutrisi ini bagus untut otot, kulit, dan peredaran darah. Di era yang serba modern dan orang-orang memiliki aktivitas yang cukup padat membuat hal-hal yang praktis menjadi yang paling dicari untuk memenuhi kebutuhan. Salah satunya ditunjukkan dengan semakin banyaknya produk-produk dalam kemasan. Minuman seperti jus jeruk pun telah banyak diproduksi dalam kemasan. Hal ini tentu memudahkan karena tidak membuat orang repot untuk membuat jus jeruk sendiri. Namun buah jeruk jika dijadikan jus jeruk segar tanpa penambahan gula sangatlah baik untuk kesehatan akan tetapi daya simpan jus jeruk segar tidaklah selama jus jeruk dalam kemasan.

Dalam industri pelayanan makanan minuman, penggunaan jus jeruk dalam kemasan lebih diminati karena daya tahan yang lebih lama dan lebih praktis didapat dibandingkan dengan jus jeruk segar, padahal jika dilihat dari pola hidup yang sehat penggunaan jus jeruk segar sangatlah baik dan memiliki kadar manis yang alami. Globalisasi membuat masyarakat menjadi makin pandai dan kritis, termasuk dalam memilih produk yang akan dikonsumsi. Berkembangnya berbagai jenis penyakit terutama yang diakibatkan oleh pola konsumsi makanan yang salah mendorong masyarakat kembali ke alam. Jus jeruk memang banyak tersedia di pasaran, tetapi hanya sedikit yang dibuat dari buah asli. Sudah saatnya memilih jus jeruk asli untuk memperoleh manfaat yang banyak. Menurut Ros-Chumillas et al. (2010), konsumsi jeruk dalam bentuk jus (sari buah) segar, kualitas gizinya lebih baik dibandingkan sari buah yang telah mengalami pengolahan. Selain kandungan vitamin $\mathrm{C}$ nya masih tinggi, citarasa buah jeruk masih tajam dan disukai.

Jeruk Siam Kintamani merupakan jeruk khas Bali yang memiliki warna kuning cerah sedikit kehijauan dan rasanya sedikit asam segar, jeruk Kintamani bisa bertahan hingga satu pekan. Jeruk Siam Kintamani dapat dimanfaatkan untuk bahan dasar jus jeruk segar dalam pembuatan minuman cocktail salah satunya cocktail Harvey Wallbanger. Adapun tujuan dari penelitian ini adalah untuk mengetahui perbandingan tingkat kesukaan minuman cocktail Harvey Wallbanger yang berbahan dasar jus jeruk siam Kintamani segar dengan jus jeruk dalam kemasan.

\section{METODE PENELITIAN}

Teknik analisis data yang dipergunakan adalah deskriptif kualitatif melalui uji organoleptik. Dalam penelitian ini yang dimaksud dengan kualitatif adalah paparan terhadap hasil akhir pembuatan Harvey Wallbanger berbahan dasar jus jeruk siam Kintamani segar 
Ni Kadek Eni Juniari

dengan minuman Harvey Wallbanger berbahan dasar jus jeruk dalam kemasan. Penelitian ini akan diuji menggunakan teknik uji organoleptik. Uji organoleptik adalah penguji bahan secara subyektif dengan pertolongan panca indra manusia, pada umumnya uji organoleptik dapat juga dikatakan penguji secara sensory evaluation yang di dasarkan atas indra penglihatan, peraba, penciuman dan rasa (Jellinek, 1985:17). Serta uji kesukaan yang disebut juga uji hedonik dengan menyebarkan angket kepada panelis. Panelis diminta tanggapan pribadinya tentang kesukaan atau sebaliknya (ketidaksukaan). Panelis dari penelitian ini terdiri dari 5 orang panelis yang memiliki keahlian dan bakat mengenai karakteristik dari cocktail (Bartender), 5 orang panelis (akademisi) yang memiliki kepekaan yang cukup baik dalam menilai beberapa rangsangan yang spesifik, dan 10 orang panelis yang menyukai atau penikmat cocktail.

Terdapat beberapa indikator yang dapat digunakan untuk menilai cocktail yaitu: (a) Acidity, (b) Sweetness, (c) Bitterness, (d) Aroma, (e) Alkohol. Menurut Katsigris \& Thomas (2007:406) cocktail yang baik dapat dicapai dengan aturan-aturan umum. Dan menyebutkan bahwa terdapat 5 karakteristik dasar dalam menilai cocktail, meliputi : (1) Acidity (keasaman), (2) Sweetness (rasa manis), (3) Bitterness (rasa pahit), (4) Flavor (rasa, aroma), (5) Balance. Sedangkan menurut Ristayana, Lia dkk (2001:30-36) indikator dalam cocktail, terdiri dari: (a) Rasa, (b) Aroma, (c) Tampilan, (d) Warna. Berdasarkan beberapa sumber diatas, maka indikator kualitas cocktail yang digunakan pada penelitian ini adalah: (a) Acidity (keasaman), (b) Sweetness (rasa manis), (c) Aroma, (d) Colour (Warna), (e) Balance, (f) Presentation (Tampilan) (Wiantara, 2016)

\section{HASIL DAN PEMBAHASAN}

\subsection{Karakteristik Jeruk Siam Kintamani}

Menurut Redaksi Sehat (2016:53) jus jeruk selain mengandung antioksidan, jeruk juga padat akan vitamin C. Nutrisi ini bagus untuk otot, kulit dan peredaran darah. Jus jeruk mengandung vitamin B dan C, magnesium, fosfor, kalsium, serta kalsium, sehinggan jus jeruk sangant baik untuk kesehatan.

Menurut Supartha dan dkk (2015:20-28) terdapat beberapa jenis jeruk yang ada di Bali salah satunya Jeruk siam Kintamani (Citrus reticula Blanco).Varietas jeruk ini berasal dari Kecamatan Kintamani, Kabupaten Bangli. Citrarasa jeruk siam Kintamani adalah manis dan segar dengan tingkat kemanisan sebesar 9-10 brix. Morfologi buah jeruk siam Kintamani adalah berbentuk bundar agak pipih, berukuran sedang, warna kulit dan daging buah pada saat matang adalah kuning-oranye. Varietas jeruk itu sesuai dibudidayakan di daerah dataran tinggi (900$1.200 \mathrm{~m} \mathrm{dpl}$ ). Jenis jeruk siam memiliki kandungan vitamin $\mathrm{C}$ buah jeruk Siam berkisar antara 20-60 mg/100 ml sari buah (Anonim, 2009). Selain kandungan vitamin C, jeruk juga mengandung komponen gula sebesar 4,93 - 7,57 g, yang terdiri dari glukosa 1,02 -1,24 g; fruktosa 1,49 - 1,58 g; sukrosa 2,19-4,90 g serta asam malat 0,18 - 0,21 g dan asam sitrat 0,80 - 1,22 g per $100 \mathrm{ml}$ sari buah (Wariyah. 2010).

\subsection{Karakteristik Jus Jeruk Kemasan}

Jus jeruk dalam kemasan merupakan olahan jus jeruk yang dibuat oleh pabrik dalam bentuk kemasan siap minum yang mempunyai daya simpan yang cukup lama. Jus jeruk dalam kemasan cenderung mengandung gula berlebih, dalam sebuah ukuran $250 \mathrm{ml}$, memiliki kandungan 115 kalori, atau setara dengan tujuh sendok teh gula. Proses jus jeruk dalam kemasan melalui beberapa tahapan yaitu pemanenan, pembersihan, grading, ekstrasi, rekonstitusi, pasteurisasi dan pengemasan.

\subsection{Prosedur Kerja}

Penelitian ini menggunakan metode eksperimen dengan melakukan uji organoleptik untuk mendapatkan perbandingan antara Harvey Wallbanger menggunakan jus jeruk siam Kintamani segar dengan Harvey Wallbanger menggunakan jus jeruk dalam kemasan. Adapun langkah uji organoleptik yang dilakukan dalam menganalisis perbandingan antara Harvey Wallbanger menggunakan jus jeruk siam Kintamani segar dengan Harvey Wallbanger 
Ni Kadek Eni Juniari

menggunakan jus jeruk dalam kemasan adalah sebagai berikut: (1) Menyiapkan formulir isian uji kesukaan yang akan digunakan saat pengujian organoleptik; (2) Menyiapkan peralatan dan bahan untuk membuat cocktail Harvey Wallbanger; (3) Menyiapkan 20 orang panelis yang akan menjadi penilai dari objek yang akan dianalisa. Panelis ini terdiri dari 5 orang panelis yang memiliki keahlian dan bakat (Bartender), 5 orang panelis (akademisi) yang memiliki kepekaan yang cukup baik dalam menilai beberapa rangsangan yang spesifik dan 10 orang panelis agak terlatih dan yang menyukai cocktail; (4) Memberikan formulir isian uji kesukaan kepada panelis untuk diisi saat pengujian dilakukan. Serta menjelaskan kepada panelis cara mengisi formulir isian; (5) Menyiapkan cocktail Harvey Wallbanger yang menggunakan jus jeruk Kintamani segar dan Harvey Wallbanger menggunakan jus jeruk dalam kemasan; (6) Panelis dipersilahkan melakukan pengujian terhadap cocktail Harvey Wallbanger; (7) Setelah panelis melakukan uji organoleptik kemudian mengumpulkan formulir isian yang sudah diisi oleh panelis; (8) Menganalisa hasil formulir isian dengan menggunakan metode komparatif antara hasil pengujian dengan teori acuan sehingga antara kedua objek yang diteliti.

\subsection{Analisis Data} hedonik).

Berikut ini adalah prosedur analisis data untuk uji organoleptik tingkat kesukaan (uji

1) Penggunaan skala hidonik pada prakteknya dapat digunakan untuk mengetahui perbedaan. Sehingga sering digunakan untuk menilai secara uji organoleptik terhadap komoditas sejenis atau produk pengembangan. Dalam penelitian ini menggunakan 4 skala hedonik diantaranya, (1) Sangat suka $=4$, (2) Suka $=3$, (3) Biasa $=2$, (4) Tidak suka $=1$.

2) Jumlah panelis yang digunakan pada saat penilaian uji organoleptik sebanyak 20 orang.

3) Uji hedonik disajikan secara acak dan dalam memberikan penilaian panelis tidak mengulang-ulang penilaian atau membanding-bandingkan contoh yang disajikan.

4) Form penilaian dibagikan kepada panelis. Penilaian dengan memberikan tanda (v) pada kolom yang sesuai.

a. Tabulasi hasil uji kesukaan kedalam tabel untuk memudahkan mencari nilai mean. Mencari nilai mean untuk menganalisa frekuensi munculnya segala kejadian yang didasarkan pada skala penelitian rumus yang digunakan adalah :

$$
\bar{X}=\frac{\sum\left(f_{1} x_{1}+f_{2} x_{2}+f_{3} x_{3}+f_{4} x_{4}+f_{5} x_{5}\right)}{f_{1}+f_{2}+f_{3}+f_{4}+f_{5}}
$$

Keterangan:

$f=$ frekuensi responden pada setiap skala likert

$x=$ nilai yang diberikan responden pada setiap skala likert

$\bar{X}=$ nilai rata-rata hitung

b. Memasukan nilai mean ke dalam interval, untuk mendapakan data kuantitatif melalui kuesioner tersebut, nilai setiap pernyataan di hitung dengan mengalikan seluruh frekuensi data dengan bobot, hasil perkalian di bagi dengan jumlah responden yang telah mengisi kuesioner dengan lengkap. Perhitungan dilakukan dengan mengklasifikasikan skor menurut interval kelas sebagai berikut:

a) Jumlah klasifikasi $(\mathrm{K})=4$ kelas

b) Range $(\mathrm{R})=$ nilai tertinggi - nilai terendah

c) Panjang kelas interval dihitung dengan rumus :

$$
\begin{aligned}
\mathrm{Ci} & =\mathrm{R}: \mathrm{K} \\
& =3: 4 \\
& =0,75
\end{aligned}
$$

Keterangan:

$\mathrm{R}=$ Range

$\mathrm{K}=$ Jumlah Klasifikasi

$\mathrm{Ci}=$ Jarak Interval Kelas

Dari perhitungan tersebut diatas, didapatkan interval kelas sebagai berikut: 
Ni Kadek Eni Juniari
a) 1 sampai $<1,75=$ Tidak Suka
b) 1,75 sampai $<2,50=$ Biasa
c) 2,50 sampa $\mathrm{i}<3,25=$ Suka
d) 3,25 sampai $\leq 4=$ Sangat Suka

Berikut ini adalah Tabel 1 tentang hasil rekapitulasi nilai rata-rata minuman cocktail Harvey Wallbanger yang menggunakan jus jeruk siam Kintamani segar dan Tabe 2 tentang hasil rekapitulasi nilai rata-rata minuman cocktail Harvey Wallbanger yang menggunakan jus jeruk dalam kemasan.

Tabel 1: Rekapitulasi Hasil Uji Organoleptik (Hedonik) Terhadap Cocktail Harvey Wallbanger Menggunakan Bahan Jus Jeruk Siam Kintamani Segar

[Sumber: Uji Organoleptik, 2019 (data diolah)]

\begin{tabular}{ccccccc}
\hline \multirow{2}{*}{$\begin{array}{c}\text { No. } \\
\text { Panelis }\end{array}$} & Acidity & Sweetness & Aroms & Colour & Balance & Presentation \\
\hline P1 & 3 & 3 & 4 & 4 & 3 & 4 \\
P2 & 3 & 2 & 4 & 3 & 3 & 3 \\
P3 & 2 & 2 & 3 & 3 & 3 & 4 \\
P4 & 3 & 3 & 4 & 3 & 2 & 4 \\
P5 & 2 & 4 & 4 & 4 & 2 & 3 \\
P6 & 3 & 4 & 3 & 4 & 3 & 4 \\
P7 & 3 & 3 & 4 & 4 & 2 & 3 \\
P8 & 2 & 4 & 3 & 3 & 2 & 3 \\
P9 & 2 & 4 & 3 & 3 & 2 & 4 \\
P10 & 4 & 4 & 4 & 4 & 3 & 2 \\
P11 & 4 & 2 & 4 & 3 & 3 & 2 \\
P12 & 3 & 3 & 3 & 3 & 3 & 3 \\
P13 & 2 & 2 & 4 & 3 & 3 & 3 \\
P14 & 2 & 3 & 3 & 4 & 3 & 3 \\
P15 & 2 & 3 & 3 & 3 & 2 & 3 \\
P16 & 4 & 3 & 4 & 3 & 2 & 4 \\
P17 & 4 & 4 & 4 & 4 & 2 & 4 \\
P18 & 3 & 2 & 4 & 4 & 3 & 4 \\
P19 & 3 & 2 & 4 & 4 & 3 & 3 \\
P20 & 3 & 4 & 3 & 4 & 2 & 3 \\
\hline Total & $\mathbf{5 7}$ & $\mathbf{6 1}$ & $\mathbf{7 2}$ & $\mathbf{7 0}$ & $\mathbf{5 1}$ & $\mathbf{6 6}$ \\
\hline Mean & $\mathbf{2 . 8 5}$ & $\mathbf{3 . 0 5}$ & $\mathbf{3 . 6 0}$ & $\mathbf{3 . 5 0}$ & $\mathbf{2 . 5 5}$ & $\mathbf{3 . 3 0}$ \\
\hline
\end{tabular}

Tabel 2: Rekapitulasi Hasil Uji Organoleptik (Uji Hedonik) Terhadap Cocktail Harvey Wallbanger Menggunakan Bahan Jus Jeruk Dalam Kemasan [Sumber: Uji Organoleptik, 2019 (data diolah)]

\begin{tabular}{ccccccc}
\hline \multirow{2}{*}{$\begin{array}{c}\text { No. } \\
\text { Panelis }\end{array}$} & Acidity & Sweetness & Aroma & Colour & Balance & Presentation \\
\hline & 1 & 1 & 2 & 2 & 2 & 1 \\
P1 & 2 & 2 & 2 & 2 & 2 & 2 \\
P2 & 1 & 1 & 2 & 1 & 2 & 2 \\
P3 & 2 & 3 & 2 & 1 & 2 & 2 \\
P4 & 2 & 2 & 3 & 2 & 3 & 2 \\
P5 & 2 & 2 & 2 & 2 & 2 & 2 \\
P6 & 2 & 2 & 3 & 3 & 2 & 1 \\
P7 & 2 & 2 & 3 & 3 & 2 & 2 \\
P8 & 1 & 3 & 2 & 2 & 2 & 2 \\
P9 & 2 & 3 & 3 & 2 & 3 & 3 \\
P10 & 2 & 2 & 3 & 2 & 2 & 3 \\
P11 & 1 & 2 & 3 & 2 & 3 & 3 \\
P12 & 1 & 3 & 2 & 2 &
\end{tabular}




\begin{tabular}{ccccccc}
\hline Ni Kadek Eni Juniari & & & & & & \\
P14 & 2 & 2 & 2 & 3 & 3 & 2 \\
P15 & 1 & 2 & 2 & 3 & 2 & 3 \\
P16 & 1 & 2 & 2 & 2 & 2 & 2 \\
P17 & 1 & 3 & 3 & 2 & 3 & 2 \\
P18 & 2 & 3 & 2 & 3 & 3 & 3 \\
P19 & 2 & 3 & 2 & 3 & 3 & 3 \\
P20 & 2 & 2 & 3 & 3 & $\mathbf{4 9}$ & $\mathbf{4 3}$ \\
\hline Total & $\mathbf{3 2}$ & $\mathbf{4 5}$ & $\mathbf{4 8}$ & $\mathbf{4 5}$ & $\mathbf{2 . 4 5}$ & $\mathbf{2 . 1 5}$ \\
\hline Mean & $\mathbf{1 . 6 0}$ & $\mathbf{2 . 2 5}$ & $\mathbf{2 . 4 0}$ & $\mathbf{2 . 2 5}$ &
\end{tabular}

Setelah didapatkan nilai rata-rata dari pembagian hasil tabulasi uji kesukaan diatas selanjutnya akan ditentukan hasil tersebut untuk mendapatkan kategori di kelas interval sesuai diagram di bawah ini, sebagai berikut:

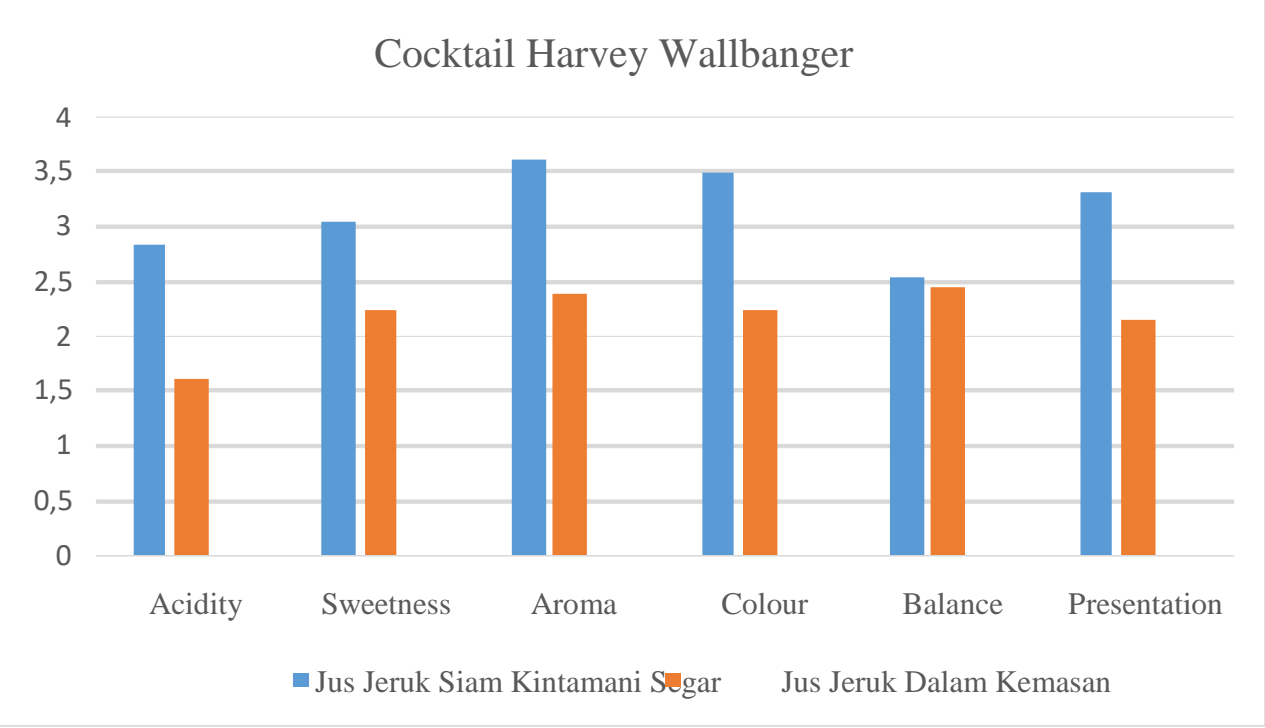

Gambar 1. Diagram Hasil Uji Organoleptik (Uji Hedonik) Cocktail Harvey Wallbanger Menggunakan Jus Jeruk Siam Kintamani Segar Dan Jus Jeruk Dalam Kemasan

[Sumber: Uji Organoleptik, 2019 (data diolah)]

Berdasarkan Gambar 1 diatas didapatkan data hasil akhir dari nilai mean dalam kriteria interpretasi pada setiap indikator cocktail Harvey Wallbanger menggunakan jus jeruk siam Kintamani segar dan jus jeruk dalam kemasan, berdasarkan acidity, sweetness, aroma, colour, balance, dan presentation. Hasil yang didapat adalah sebagai berikut:

1) Acidity

Tingkat acidity Harvey Wallbanger menggunakan jus jeruk siam Kintamani segar mendapatkan nilai mean sebesar 2,85 dan nilai kriteria interpretasinya adalah suka sedangkan Harvey Wallbanger berbahan jus jeruk dalam kemasan yang mendapat nilai mean sebesar 1,60 dengan interpretasi tidak suka. Hal ini menunjukkan bahwa kadar keasaman minuman Harvey Wallbanger dengan menggunakan jus jeruk siam Kintamani segar disukai oleh panelis dikarenaka kadar asam alami yang dihasilkan oleh jus jeruk segra.

2) Sweetness

Dilihat dari Sweetness Harvey Wallbanger berbahan jus jeruk siam Kintamani segar mendapatkan nilai mean sebesar 3,05 dengan nilai kriteria interpretasinya adalah suka sedangkan Harvey Wallbanger berbahan jus jeruk dalam kemasan yang mendapat nilai mean sebesar 2,25 dengan interpretasi biasa. Hal ini menunjukkan bahwa rasa manis minuman Harvey Wallbanger dengan menggunakan jus jeruk siam Kintamani segar disukai oleh panelis yang dikarenakan rasa manis alami yang dihasilkan jus jeruk segar sangat pas dikombinasikan pada minuman ini.

3) Aroma 
Ni Kadek Eni Juniari

Aroma yang dihasilkan dari Harvey Wallbanger menggunakan jus jeruk siam Kintamani segar mendapatkan nilai mean sebesar 3,60 dengan nilai kriteria interpretasinya adalah sangat suka sedangkan Harvey Wallbanger berbahan jus jeruk dalam kemasan yang mendapat nilai mean sebesar 2,40 dengan interpretasi biasa. Hal ini menunjukkan bahwa aroma minuman Harvey Wallbanger yang menggunakan jus jeruk siam Kintamani segar sangat disukai oleh panelis dikarenakan aroma buah jeruk segar lebih tercium pada minuman ini.

4) Colour

Hasil dari colour cocktail Harvey Wallbanger berbahan jus jeruk siam Kintamani segar mendapatkan nilai mean sebesar 3,50 dengan nilai kriteria interpretasinya adalah sangat suka sedangkan Harvey Wallbanger berbahan jus jeruk dalam kemasan yang mendapat nilai mean sebesar 2,25 dengan interpretasi biasa. Hal ini menunjukkan bahwa minuman Harvey Wallbanger yang menggunakan jus jeruk siam Kintamani segar sangat disukai oleh panelis karena memiliki warna yang lebih cerah dan menarik dengan warna terang.

5) Balance

Hasil dari balance cocktail Harvey Wallbanger menggunakan jus jeruk siam Kintamani segar mendapatkan nilai mean sebesar 2,55 dengan nilai kriteria interpretasinya adalah suka sedangkan Harvey Wallbanger berbahan jus jeruk dalam kemasan yang mendapat nilai mean sebesar 2,45 dengan interpretasi biasa. Hal ini menunjukkan bahwa minuman Harvey Wallbanger dengan menggunakan jus jeruk siam Kintamni segar menghasilkan tingkat keseimbangan rasa (balance) yang disukai oleh panelis, karena perpaduan semua bahan dengan jus jeruk segar mampu menghasilkan balance rasa yang nikmat.

6) Presentation: Dari tingkat

presentation Harvey Wallbanger berbahan jus jeruk siam Kintamani segar mendapatkan nilai mean sebesar 3,30 dengan nilai kriteria interpretasinya adalah suka sedangkan Harvey Wallbanger berbahan jus jeruk dalam kemasan yang mendapat nilai mean sebesar 2,15 dengan interpretasi biasa. Hal ini menunjukkan bahwa presentation atau tampilan akhir minuman Harvey Wallbanger dengan jus jeruk siam Kintamani segar disukai oleh panelis karena tampilan akhir minuman yang lebih menarik.

Secara keseluruhan jika dilihat dari nilai rata-rata total maka hasil yang didapat cocktail Harvey Wallbanger menggunakan jus jeruk siam Kintamani segar mendapat nilai sebesar 3,30 dengan nilai interpretasinya adalah sangat suka sedangkan cocktail Harvey Wallbanger menggunakan jus jeruk dalam kemasan mendapatkan nilai sebesar 2,49 dengan nilai interpretasinya adalah biasa. Hasil uji organoleptik menggunakan uji hedonik ini menunjukkan bahwa minuman cocktail Harvey Wallbanger yang menggunakan bahan dasar jus jeruk siam Kintamani segar lebih disukai. Selain itu, penggunaan jus jeruk segar dalam setiap pembuatan minuman cocktail Harvey Wallbanger juga dapat membantu meningkatkan penggunaan produk buah lokal yang nantinya dapat menguntungkan para petani buah lokal. Gambar 2 menunjukkan perbedaan hasil minuman cocktail Harvey Wallbanger berbahan dasar jus jeruk siam Kintamani segar dengan Harvey Wallbanger berbahan jus jeruk dalam kemasan.

\begin{tabular}{cc}
\hline Gambar & Keterangan \\
\hline
\end{tabular}

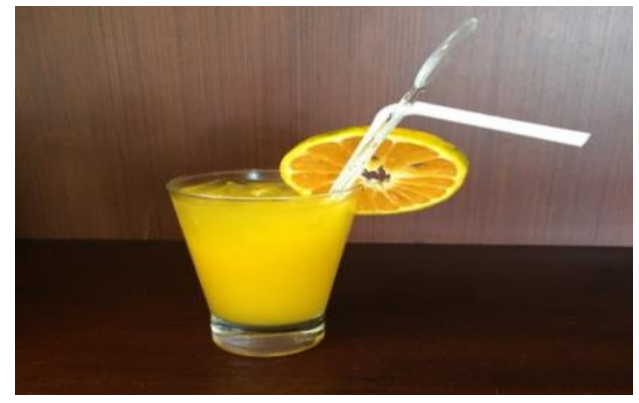

Harvey Wallbanger menggunakan jus jeruk siam Kintamani segar 


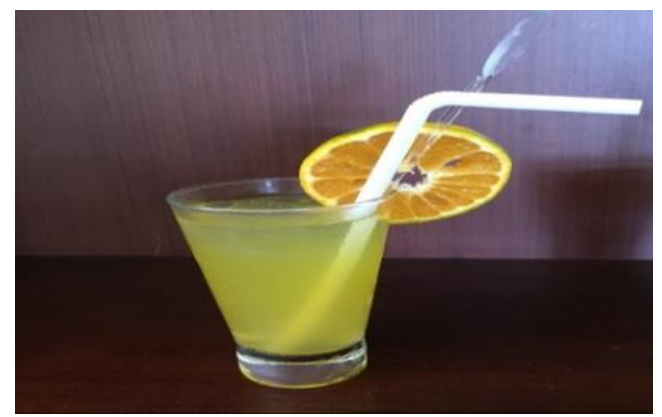

Harvey Wallbanger menggunakan jus jeruk dalam kemasan

Gambar 2. Colour Harvey Wallbanger Menggunakan Jus Jeruk Kintamani Segar dengan Harvey Wallbanger Menggunakan Jus Jeruk Dalam Kemasan

[Sumber: Uji Organoleptik,2018]

\section{KESIMPULAN}

Berdasarkan analisis data, setelah dilakukan uji organoleptik cocktail Harvey Wallbanger, maka dapat disimpulkan dari hasil uji hedonik cocktail Harvey Wallbanger menggunakan jus jeruk siam Kintamani segar mendapatkan rata-rata total 3,30 mendapat interpretasi sangat suka sedangkan cocktail Harvey Wallbanger menggunakan jus jeruk dalam kemasan mendapat rata-rata 2,49 dan mendapat interpretasi biasa. Dari hasil uji hedonik cocktail Harvey Wallbanger menggunakan jus jeruk Kintamani segar sangat disukai oleh panelis.

Berdasarkan kesimpulan maka dapat disarankan pembuatan cocktail Harvey Wallbanger lebih baik menggunakan jus jeruk segar karena dari hasil uji organoleptik tampilan dari jus jeruk segar lebih menarik dan juga jus jeruk segar mengandung bahan alami yang sangat baik untuk kesehatan serta penggunaaan jus jeruk siam Kintamani dapat memanfaatkan hasil pertanian produk lokal dan Cocktail Harvey Wallbanger menggunakan jus jeruk siam Kintamani segar dapat menjadi inovasi baru bagi industri minuman dikarenakan berdasarkan hasil uji organoleptik Harvey Wallbanger menggunakan jus jeruk siam Kintamani segar lebih disukai.

\section{DAFTAR PUSTAKA}

Calabrese, S. (2012).The Complete Home Bartender's Guide. London : Lynn Bryan

Katsigris, C. \& Thomas C. (2006). The Bar \& Beverage Book Fourth Edition. United States Jhon Wiley \& Sons, Inc.

Husein, U. (2008). Metode Penelitian Untuk Skripsi dan Tesis Bisnis. Jakarta. PT Rajagrafindo Persada.

Jelinek, G. (1985). Sensory Evaluation of Food. England: Ellis Horwood.

Kartika, B. (1988). Pedoman Uji Indrawi Bahan Pangan. Yogyakarta: PAU Pangandan Gizi UGM.

Lumanauw, F. (2000). Bar dan Minuman. Jakarta: PT: Gramedia Pustaka Utama

McWilliams, M. (1997). Foods Experimental Perpectives. United States of American: Macmillan Publishing Company.

Nuraini, D. (2017). Pro-Kontra Aneka Minuman Bagi Kesehatan. Yogyakarta: GAVA MEDIA.

Noor, E. dkk. Proses Mikropiltrasi untuk penghilangan Limonin dan Naringin pada Jus Jeruk Siam.Teknologi Industri Pertanian. Institut Pertanian Bogor.

Prastowo, A. (2011). Metode Penelitian Kualitatif dalam Perspektif Rancangan Penelitian. Yogyakarta: Ar-Ruzz Media.

Ridwandan, A. (2007). Rumus dan Data dalam Aplikasi Statistika. Bandung: Alfabeta.

Ristayana, L. Dkk. (2000) tt. Kajian Kadar Gula Sirup dan Tingkat Kematangan Buah. Online Jurnal, Studi proses pengolahan koktail dari tanaman nipah (Nypa Fruticans Wurm)

Ros-Chumillas, M. dkk. (2010). Quality and Shelf Life of Orange Juice Aseptically Package in PET bottles. Technical University of Cartagena., Agricultural Equipment and Food Engineering Department

Sehat, R. (2016). Kitab Buah \& Sayur. Yogyakarta: Scone Hope.

Sihite, R. (2006). BAR (MinumanAlkohol). Surabaya: SIC. 
Ni Kadek Eni Juniari

Sutomo, B. (2016). Jus \& Ramuan Herbal. Jakarta: PT. Kawan Pustaka.

Sugiyono. (2013). Statistika untuk Penelitian. Bandung: Alfabeta.

Supartha, K. dkk. (2015). Profil Jeruk Gianyar. Fakultas Pertanian Universitas Udayana.

Soekarno, S. T. (1985). Penilaian Organoleptik Untuk Industri Pangan dan Hasil Pertanian. Jakarta: Bharata Karya Aksara.

Wiantara,I.G.N . (2016). Bartending \& Mixiologi. Yogyakarta: ANDI. http://kindredcocktails.com/review/craf-cocktail-making-theor-and-structure-acidity yang diakses pada tanggal 10 Juni 2019 pada pukul 09.00 WITA. 